\title{
DEPRESSÃO E BURNOUT
}

\section{EM PASTORES}

\section{DEPRESSION AND BURNOUT IN PASTORS}

Fabiana Josefa do Nascimento Sousa ${ }^{83}$ Sérgio da Cunha Falcão ${ }^{84}$ Ana Beatriz de Andrade Borba Delgado ${ }^{85}$ Victória Emmanuely de Melo ${ }^{86}$

83 Mestre em Neuropsiquiatria e Ciências do Comportamento pela UFPE. Especialista em Saúde Mental pela UFCG e Especialista em Neuropsicologia pela UNIPE. Graduada em Psicologia pela UEPB graduação em Licenciatura Plena pela Universidade Estadual da Paraíba (2004) e (2008). Especialização em Saúde Mental (UFCG) e Especialização em Neuropsicologia (Unipê). Atualmente é psicóloga clínica, Professora e Parecerista do comitê de ética em pesquisa da Centro Universitário do Vale do Ipojuca Unifavip/Wyden, Professora da FICV. Email: fabianajnsousa@gmail.com

84 Doutorando em Ciências da Religião pela UNICAP. Mestre em Saúde Pública pela UEPB. Graduado em Teologia pela FTSA e em Medicina pela UFPB. Professor de Teologia da FICV. Médico Professor do Departamento de Cirurgia da UFPB. Residência Médica em Cirurgia Geral e Cirurgia Plástica UNIFESP. Email: sergioeadeliafalcao@gmail.com 85 Graduanda em Teologia pela Faculdade Internacional Cidade Viva-FICV. Graduanda em Relações Internacionais pela UEPB. Email: anabiaandrade14@gmail.com 86 Graduanda em Psicologia pelo Centro Universitário do Vale do Ipojuca Unifavip/Wyden. Email: victoriaemmanuely2@gmail.com 


\section{RESUMO}

A saúde mental de pastores é um tema pouco debatido embora seja uma evidência atual. Com efeito, estudos sobre a condição psíquica de pastores, hodiernamente, é de indubitável importância, uma vez que a depressão e burnout têm ultrapassado níveis aceitáveis de normalidade. Ainda são tímidas as publicações com este objeto de estudo. Este fato se justifica a importância de trazer à tona os fatores desencadeantes destes transtornos com efeitos alarmantes no cenário eclesiástico e na vida dos indivíduos pastores. Assim, o objetivo é provocar reflexão sobre depressão e burnout em pastores a partir de uma revisão de literatura. $\mathrm{Na}$ narrativa bíblica tem-se o registro do líder religioso Moisés que se apresentava com esgotamento físico e emocional, e seu sogro Jetro o orientou a delegar funções aos; no que diz respeito às depressões temos relatos de alterações patológicas do humor em Davi e Saul, por exemplo. Concepções equivocadas de que pastores são para "resolver as coisas de Deus" e o limite é a exaustão têm contribuído para constituição de quadro alarmante de pessoas que cuidam dos outros, ao custo de tornarem-se sufocadas, angustiadas, em pânico e emocionalmente adoecidas. Algumas são levadas ao ponto da ideação ou cometimento de atos suicidas.

\section{PALAVRAS-CHAVE}

Depressão; Burnout; Pastores; Espiritualidade.

\section{ABSTRACT}

The mental health of evangelical pastors is a theme which despite of been at evidence in the present days, has been little debated. Studies regarding the psychic conditions of pastors are of great importance since the number of cases of Depression and Burnout Syndrome within this group has surpassed acceptable levels. Publications dealing with this issue are still rare. This fact shows the importance of a study that raises some of the triggering factors of these disorders, which have produced alarming effects in the ecclesiastic scenery, and to pastors themselves. The aim of this article is to provoke a reflection about Depression and Burnout Syndrome in pastors through a literary review. In the Biblical 
narrative there is a record about the religious leader Moses who showed evidences of physical and emotional exhaustion. Because of this his father in law Jethro advised him to delegate some of his responsibilities to others. Regarding Depression there are some reports about the pathological changes of humor of David and Solomon, for example. Mistaken conceptions such as the one which assumes that pastors exist "to do God's work" to the limit of exhaustion have contributed to the creation of an alarming picture where some people take care of others at the cost of becoming suffocated, distressed, in panic, and emotionally sick. Some advance to the point of idealizing or perpetrating suicide acts.

\section{KEYWORDS}

Depression; Burnout; Pastors; Spirituality

\section{INTRODUÇÃO}

Diante dos efeitos corrosivos sobre a boa criação de Deus instaurados pelo mau uso da liberdade humana (queda), haja vista a perspectiva bíblica, as doenças psicossomáticas sobrepõem à normalidade, reverberando a sobrecarga e o esgotamento emocionais; "toda a criação geme como em dores de parto" (ROMANOS 8.22; WOLTERS, 2006). Destarte, a saúde psicoemocional tem sofrido um bombardeio conflitante que corrobora os efeitos da depressão. Nesse contexto, analisando o cenário das igrejas evangélicas hodiernas, a liderança pastoral tem vivenciado de forma exacerbada essa realidade, afetando diretamente naquilo que tange a saúde mental dos pastores, visto as circunstâncias as quais deveriam lidar com excelência, apesar da carga negativa (TOMIC, Welko; TOMIC, David; EVERS, 2004).

Dessa maneira, é costumeiro que líderes religiosos ocupem posições de demasiadas responsabilidades, tornando-se sujeitos a avaliações quase que todo o tempo. Assim, é usual que eles sofram oposições, dores e muitas tensões enquanto ocupam tal cargo. A Bíblia relata vários casos de líderes religiosos que sofreram, deixando claro que isso não é uma situação que atinge apenas os mais atuais (BUHR, 2015).

No ano de 2015, a prevalência da ansiedade foi de 3,6\% no mundo e 9,3\% no Brasil; enquanto a depressão pode ser considerada a doença do século, sendo que sua forma grave é 
atualmente a principal causa de incapacidade em todo o mundo e ocupa o quarto lugar entre as dez principais causas de patologia, a nível mundial. E, se estiverem corretas as projeções, nos próximos 20 anos, a depressão será a segunda das principais causas de doenças no mundo, perdendo apenas para a VIH/SIDA e sendo mais frequente que a doença cardíaca isquêmica. Essa patologia acomete 4,4\% da população mundial - cerca de 300 milhões de pessoas - e 5,8\% dos brasileiros (ORGANIZAÇÃO PAN-AMERICANA DE SAÚDE, 2018; ORGANIZAÇÃO MUNDIAL DE SAÚDE, 2002, 2008; WORLD HEALTH ORGANIZATION, 2017; MATHERS; LONCAR, 2006). De acordo com Nunes, Souza e Castro (2018), os conceitos sobre depressão na igreja, apesar de serem reconhecidos nos dias atuais, ainda possibilitam subsistência de diversas ideias equivocadas no que diz respeito a diagnóstico. Para os referidos autores, a depressão é um transtorno multidimensional e faz-se necessária a interlocução dos estudos deste transtorno com a espiritualidade, uma vez que a espiritualidade é uma esfera que constitui a vida de pastores.

Por sua vez, a síndrome de burnout foi primeiro descrita por Herbert Freudenberger (1974), da seguinte forma:

O dicionário define o verbo "esgotar-se" como "falhar, desgastar-se ou esgotar-se, exigindo excessivamente energia, força ou recursos". E é exatamente isso que acontece quando um membro da equipe de uma instituição alternativa [que trata dependentes químicos] queima toda sua energia por qualquer motivo e se torna inoperante para todas as intenções e propósitos. (FREUDENBERGER，1974，p. 159-160, tradução nossa).

Nessa primeira publicação, além de ter sido escrita com letras minúsculas - porque não se referia a um nome próprio/epônimo -, a palavra foi originalmente utilizada como um verbo e escrita na forma "burn-out", em vez de "burnout"; reforçando o fato de que tal morbidade está relacionada a uma exaustão ou perda/queima excessiva de energia para fora. $\mathrm{Na}$ mesma época, Christina Maslach e Ayala Pines (1977) publicaram estudos que descreviam uma síndrome de esgotamento em profissionais que cuidavam de pessoas, ulteriormente denominada de síndrome de burnout; culminando com a criação 
do Maslach Burnout Inventory (MBI) (MASLACH; JACKSON; LEITER, 1997). Assim, é possível inteirar que se trata de uma síndrome psicológica produzida a partir de respostas distressoras ateadas a partir do trabalho (VASCONCELLOS, 2015 apud NAKANO; NERY; VASCONCELLOS, 2018). Quando pesquisamos 0 descritor "burnout" na Biblioteca Virtual em Saúde (2019), surge a opção "Burnout Syndrome", conceituada como "reação excessiva ao estresse causada pelo ambiente que pode ser caracterizada por sentimentos de exaustão física e emocional, somados a uma sensação de frustração e fracasso". Essa base de dados registra como sinônimos de burnout os termos: burn-out, esgotamento da escola, esgotamento do cuidador, esgotamento do estudante, exaustão da escola, exaustão do cuidador, exaustão do estudante e síndrome do esgotamento. De acordo com Malasch et al (2001), essa reação manifesta-se a partir de três dimensões, sendo estas: esgotamento emocional, despersonalização e reduzida realização profissional. A primeira dimensão diz respeito a um sentimento de sobrecarga, enquanto que a segunda se remete a atitudes de frieza e distanciamento quanto aos outros colaboradores do trabalho. A terceira por sua vez, refere-se a um sentimento de incompetência e inutilidade, desencadeando uma falta de produção e de realização profissional.

Esses desvios da normalidade psíquica podem acometer profissionais das mais diversas áreas, incluindo pessoas que laboram no ministério pastoral. Segundo Pérsio Ribeiro Gomes de Deus (2009), as pesquisas realizadas nesse público têm asseverado que o número de pastores que desenvolvem psicopatologias, a partir da execução da profissão, tem aumentado. O presente artigo tem como objetivo refletir acerca da depressão e da síndrome de burnout em pastores evangélicos, no contexto da teologia prática cristã. Serão apresentados conceitos desses temas e reflexão crítica aplicativa. A metodologia utilizada foi do tipo pesquisa bibliográfica não exaustiva referente ao tema do presente trabalho e utilizadas como lentes interpretativas a psicologia, a psiquiatria e a teologia cristã.

\section{O TRABALHO PASTORAL}

Numa tentativa de atender às necessidades, demandas e expectativas da comunidade religiosa, bem como a realização das mais diversas funções do ministério pastoral, muitos pastores 
imergem em uma situação, quase sempre integral, tentame de realização profissional. Enfrentando exigências da família e da sociedade de como devem ser ou agir. As demandas desta profissão costumam ser intensas e produzem desgastes físicos, emocionais e espirituais, aumentando os riscos de doenças psicossomáticas.

O aparecimento de doenças é comum, apresentando-se principalmente em diagnósticos físicos, como: diabetes, hipertensão, doenças cardiovasculares e obesidade, desencadeando pensamentos causais, em geral, apenas orgânicos sobre estas. Porém, considerando o homem como ser biopsicossocial, é possível afirmar que até mesmo as doenças físicas podem apresentar causas psicoemocionais e vice-versa. Contudo, o aparecimento de transtornos mentais, dentro da igreja, muitas vezes não tem sido tratado com a devida importância. Tal fato, tem possibilitado, via de regra, interpretações opulentas de preconceitos e dogmas religiosos (AMORIM JUNIOR; ARAUJO; SILVA, 2019).

A subjetividade da espiritualidade tem tomado cada vez mais espaço dentro dos contextos anexados à saúde mental. Temas como esses, tornam-se fundamental no que diz respeito aos profissionais da saúde que têm como objetivo se ater a uma visão apurada de todas as esferas que constituem um ser humano (NUNES; SOUZA; CASTRO, 2018).

A ideia que o pastor é apenas um ser escolhido para cuidar das "coisas de Deus", implica, muitas vezes subjetivamente, em esquecer-se de que apesar disso, o sujeito por trás da função, ainda é um ser humano, e como tal, possui necessidades físicas, psicológicas e socioemocionais. E, por diversas vezes, a atividade pastoral é desconsiderada como profissão e com todas as suas implicações (AMORIM JUNIOR; ARAUJO; SILVA, 2019).

O pastor é compreendido como alguém separado para servir a comunidade religiosa, independentemente de qualquer necessidade humana que este possua, tais como: descanso, cuidado da saúde física e mental, financeiras e até mesmo fisiológicas.

Ao decorrer das repostas às exigências e demandas que surgem, pastores acabam possuindo um ritmo de trabalho intenso e constante. Dificultando, muitas vezes, a determinação de limites de tempo e descanso (EBERT; SOBOLL, 2009). Hodiernamente, tem-se exigido dos líderes maior variabilidade de atividades e competências, assim como maior flexibilidade de horário e 
decisões mais dinâmicas e rápidas com as demandas dos fiéis. Dessa forma, não basta apenas assumir responsabilidades de pastor, é necessário também assumir papéis correspondentes a psicólogos, advogados e até mesmo políticos (SILVA, 2004).

Nessa perspectiva, é necessário salientar que os pastores também carecem de apoio emocional, visto que absorvem muitas situações conflituosas e problemáticas, além de todas essas situações serem agravadas pelos seus próprios problemas vivenciados de forma individual. Diante disso, os dados da pesquisa feita pelo Francis A. Schaeffer Institute of Church Leadership Development (2016), ratificam o quão alarmante é a situação atual no que tange o ministério pastoral: " $80 \%$ dos pastores acreditam que o ministério pastoral tem afetado negativamente suas famílias, $70 \%$ deles crê que não possuem um amigo próximo. Outro dado é que $70 \%$ dos pastores lutam contra a depressão".

Diante desses dados, fica claro o quanto o trabalho pastoral exige dedicação significativa que, quando extrapolada por fatores diversos, pode gerar doença, sofrimento e até suicídio:

O exercício do ministério tem sempre de se dar em condições saudáveis. O exercício do ministério muitas vezes é comprometido e alterado pelas circunstâncias concretas nas quais se desenvolve uma [...] dessas circunstâncias é a sobrecarga de ação e preocupação pastorais. Essa sobrecarga é, com muita frequência geradora de uma ansiedade crescente que pode progressivamente tornar-se intolerável, a ponto [...] de provocar no fim, um estado prolongado ou passageiro de saturação psíquica que dificulta muito o exercício espiritual do ministério. (URIARTE, 2000, p.20)

\section{DEPRESSÃO EM PASTORES}

O alarmante crescimento dos números estatísticos sobre a depressão torna necessária uma reflexão em várias áreas da atividade humana e o reconhecimento de que estamos diante de um prioritário problema de saúde pública (CONRAD, 2007; DALGALLARONDO, 2000). Com base em dados coletados em 2015, estima-se que o número total de pessoas no mundo portadoras de 
depressão é de 322 milhões. Essa população aumentou 18,4\% entre 2005 e 2015, devido ao crescimento da população global e por um aumento proporcional das faixas etárias nas quais a depressão é mais prevalente - 55 a 74 anos de idade. Quem tem depressão grave tem uma chance 40 a $60 \%$ maior de morrer prematuramente do que a população em geral, devido a problemas de saúde física que muitas vezes são deixados sem assistência (como câncer, doenças cardiovasculares, diabetes e infecção por HIV) e suicídio. Esse último agravo acomete cerca de 800 mil pessoas a cada ano, sendo a segunda causa de morte entre pessoas com idade entre 15 e 29 anos (WORLD HEALTH ORGANIZATION, 2013; ORGANIZAÇÃO PAN-AMERICANA DE SAÚDE, 2018; WORLD HEALTH ORGANIZATION, 2017).

A respeito dessa fatalidade citada, faz-se importante esclarecermos que a divulgação repetitiva de suicídios ou de detalhes de um mesmo caso está ligada ao aumento da taxa de novos casos, enquanto matérias jornalísticas sobre pessoas que relataram ideação suicida sem consumar o fato estão associadas a diminuição das taxas de suicídio (NIEDERKROTENTHALER et al., 2010). Segundo Stack (2018), atividades religiosas diminuem o risco de suicídio, conforme estudo da relação entre um índice de atividades religiosas e dados concretos individuais (familiares) sobre 1.385 suicídios consumados e 15.410 mortes por outras causas.

Segundo a American Psychiatric Association (2014), em seu Manual Diagnóstico e Estatístico de Transtornos Mentais (Diagnostic and Statistical Manual of Mental Disorders - DSM-5), existem vários tipos de depressão, tendo estas como características comuns a presença de humor triste, vazio ou irritável, acompanhado de alterações cognitivas e físicas ao funcionamento do sujeito. O DSM-5 classifica a depressão em duas subcategorias principais: a) transtorno depressivo maior/episódio depressivo (leve, moderado ou grave), com humor deprimido, perda de interesse e prazer por atividades que antes proporcionavam energia e alegria; b) e transtorno depressivo persistente (distimia), uma forma persistente ou crônica de depressão leve (AMERICAN PSYCHIATRIC ASSOCIATION, 2014). Essa patologia é marcada também por um aumento ou diminuição de apetite, cansaço, baixa autoestima, sentimentos de culpabilidade, dificuldade de concentração, ideação e/ou tentativas suicidas (MENDEZ; OLIVARES; ROS, 2005). 
No contexto das atividades laborativas dos pastores, observando a demanda ministerial incumbida a esses profissionais, muitas vezes voluntários, é inevitável que isso traga malefícios; pois lidam com problemas diversos de cunho familiar até o âmbito espiritual, em que o aconselhamento e o acompanhamento fazem-se necessário, sobrepondo assim o seu cuidado com a própria saúde, afirmando a negligência e a solidão.

Em tese de livre docência feita pelo psiquiatra Francisco Lotufo Neto (1997), na qual estudou uma amostra de pastores da cidade de São Paulo, o autor encontrou maior prevalência de transtornos mentais nesses profissionais (47\%) quando comparados com a população geral de São Paulo à época (31\%), sendo que a depressão foi a doença mais comumente encontrada nesses ministros protestantes $(16,4 \%)$.

Em pesquisa mais recente, realizada pelo psiquiatra Pérsio de Deus (2008), dentre 50 prontuários de pacientes cristãos com depressão, em um período de seis meses, 13 eram de pastores. Destes, apenas três consideravam a possibilidade de portar a doença. No que tange às causalidades, dois relacionaram ao pecado e falta de fé, um a ações demoníacas e um não sabia a causa. Levando-nos a uma reflexão acerca das possíveis dificuldades do mundo cristão em visualizar a doença como de fato doença. Contudo, não podemos desconsiderar aqueles fatores, que podem ou não estar relacionados ao aparecimento da doença, visto que o sujeito credor compreende a espiritualidade e seus respectivos fatores como causalidades para os mais diversos quadros clínicos.

A mesma pesquisa mostrou que nove, dentre os 13, afirmavam como causalidade da depressão os distresses advindos da atividade pastoral. As explicações trazidas por estes, diz respeito aos seguintes fatores: problemas com outros líderes, existência de problemas financeiros proveniente da baixa remuneração profissional, problemas conjugais, dificuldade de dedicação de tempo rentável à família e amigos, mudanças constantes de campos de trabalho, dentre outros.

O autor ainda completa que em razão das condições particulares do pastorado, estes apresentam uma extrema dificuldade em lidar com estados de fragilização, como o fato de estar doente, como exemplo. “O pastor, líder carismático, ungido, investido da imagem do 'homem de Deus' na comunidade, tem que estar sempre pronto e disponível para as atividades pastorais" (DEUS, 2009, p. 199). Pastores assumem posições de modelos de 
conduta espiritual e comportamental para os membros da organização religiosa no qual estão inseridos. É possível, que estes sentimentos de tristezas e angústias passem uma impressão de "mau testemunho", demonstrando assim, para alguns, um sinal de fraqueza e incapacidade de liderar (NUNES; SOUZA; CASTRO, 2018). Segundo Deus (2008), a maior causa de depressão nos pastores está adstrita ao estresse de sua profissão, aos problemas em sua igreja local, à baixa ou nula remuneração financeira e a falta de apoio e compreensão da igreja.

\section{BURNOUT EM PASTORES}

Segundo Beebe e Doolittle (apud NAKANO; NERY; VASCONCELLOS, 2018) frequentemente é observado altos níveis de burnout em pastores. Leiter, Bakker e Maslach (2014) apontam a persistência da síndrome de burnout como uma das maiores crises de carreiras do século 21.

Grosch e Olsen (2000) apontam que, no que diz respeito à síndrome de burnout no ministério, é possível a derivação de duas fontes simultâneas. Sendo a primeira, fatores externos, como: burocracia, dificuldades de trabalho e falta de apoio administrativo; e a segunda, por sua vez, fatores intrapessoais, a exemplo de narcisismos, perfeccionismo e auto idealismo.

Já Hart (1984 apud SILVA, 2003), sugere quatro características do trabalho pastoral que é capaz de contribuir para o aparecimento de sinais e sintomas de burnout, sendo: (1) ministério é direcionado para as pessoas; (2) os limites do trabalho pastoral não são claros; (3) há falta de critérios para medir o resultado do trabalho; (4) frequentemente o ministro é colocado em um pedestal." (SILVA, 2003, p. 5)

Ademais, Jackson-Jordam (2013, apud NAKANO; NERY; VASCONCELLOS, 2018), aponta, dentre outros, que fatores como relacionamentos fora do contexto religioso, habilidades interpessoais, espiritualidade pessoal e existência de alta expectativa pelos fiéis permeiam a questão de burnout no clero de maneira geral.

Desde a década de 80, vários estudos nos Estados Unidos da América, descrevem uma disseminação de burnout em pastores. Uma pesquisa desenvolvida por Crousher em 2000 relata que três entre quatro pastores apresentam níveis de distresse, causando angústias, preocupações e outros sentimentos ditos 
negativos (SILVA, 2003).

Curiosamente, segundo Ufema (2001 apud SILVA, 2003),

burnout pastoral ocorre quando tenta usar as próprias energias para realização de algo que deveria ser alcançado através, unicamente, das energias advindas de Deus. Ou seja, trabalhar na carne para alcançar algo que deveria ser alcançado pelo Espírito (SILVA, 2003).

Numa pesquisa realizada com 881 padres latinoamericanos e publicada em 2014, constatou-se que a exaustão é o principal fator para burnout e considerações importantes a apontar é que vícios ao álcool e tabaco podem, também, estar associados ao burnout (HERRERA et al, 2014).

Segundo um estudo realizado por Nakano, Nery e Vasconcellos (2018), com 20 pastores, foi observado que a incidência de sinais e sintomas da síndrome de burnout é maior naqueles que trabalham sozinhos. Os autores ainda defendem o trabalho em equipe como preventivo, categorizando-se, segundo os autores, como anti-burnout. Desta forma, é possível conjecturar que pastores que delegam atividades para outros líderes, de maneira equilibrada, gozariam de uma menor possibilidade de desenvolver a síndrome. Assim como, outras doenças psicossomáticas advindas de um nível de distresse.

De acordo com Silva (2003), uma forma de prevenir o burnout pastoral seria a devida capacitação de outros líderes dentro das denominações religiosas afim de,ajudá-los nas responsabilidades administrativas, bem como outras funções advindas do cargo.

\section{SUICÍDIO? E AGORA JOSÉ?}

Dentre tantas disfunções que possam acarretar em suicídios, não é possível descartar as depressões e a síndrome de burnout, visto que estas podem ser fontes desse ato de dor, tanto pelo adoecimento mental, como quanto ao físico.

Os versos do poema José, escritos por Carlos Drumond de Andrade em 1942, expressam parte da noite escura de quem, diante de uma incapacidade de sentir prazer em atividades normalmente agradáveis, pensa em tomar o lugar de Deus e retirar sua própria vida:

Está sem mulher, 


$$
\begin{array}{r}
\text { está sem discurso, } \\
\text { está sem carinho, } \\
\text { já não pode beber, } \\
\text { já não pode fumar, } \\
\text { cuspir já não pode, } \\
\text { a noite esfriou, } \\
\text { o dia não veio, } \\
\text { o bonde não veio, } \\
\text { o riso não veio, } \\
\text { não veio a utopia } \\
\text { e tudo acabou } \\
\text { e tudo fugiu } \\
\text { e tudo mofou, } \\
\text { e agora, José? } \\
\text { (ANDRADE, 2019) }
\end{array}
$$

Segundo Dejours e Bègue (2010), aquele que desisti de viver, não possui mais prazer em trabalhar e como tal não vê mais sentido na atividade, sente-se inútil. Na sociedade ocidental contemporânea, o trabalho é exigência de sobrevivência e fonte de status social. É através do trabalho que muitos sentem sua identidade sendo formada.

A instabilidade financeira, o risco de perder o emprego ou de não bater metas, é para muitos, uma tortura. Desta forma, o colaborador submete-se a condições opressoras de trabalho e cargas horárias excessivas, no que tange a saúde do sujeito (SILVA, 2018).

Dois em cada 10 casos de depressão se tornam crônicos, e dois terços das pessoas com depressão não fazem tratamento. Além disso, "a maioria dos pacientes não tratados tentará suicídio pelo menos uma vez na vida" e, destes, $17 \%$ conseguem se matar (GOMES, 2011, p. 83). Sendo hoje a morte vista como forma de fracasso, o suicídio é visto como ato de vergonha. Entretanto, dada como vergonha ou não, a morte é um fato inevitável e imprevisível. O suicídio por sua vez, pode ser evitado se reconhecido e visto na sua importância. Devendo deste modo, deixar de ser um tabu ou um assunto não falado, principalmente, dentro das igrejas, visto que, o número de ministro que cometem suicídio tem aumentado. Em 2017, três padres cometeram suicídio em um espaço de tempo de 15 dias, ainda neste ano quatro pastores cometeram tal ato (SILVA, 2018, p. 39).

Entretanto, em certa coerência com os versos de Carlos 
Drumond, quando ele afirma que nem mesmo a morte é solução plausível, mas discordando dele em relação a ausência de sentido de vida e apoio divino e comunitário, os pastores acometidos por doenças mentais devem buscar tratamento psiquiátrico/psicológico e apoio de outros pastores e de sua própria comunidade; os quais devem estar cientes da necessidade não preconceituosa de que o uso de medicamentos prescritos por médico psiquiatra e da psicoterapia feita por psicólogo/psiquiatra são indispensáveis na maioria dos caos. Mais ainda, membros da comunidade com alguma experiência em aconselhar/cuidar ou líderes de ministérios da igreja devem estar atentos a situações individuais que aumentam os riscos de suicídio, como: intenção anterior de suicídio; transtornos mentais, principalmente ansiedade, depressão e uso nocivo de álcool ou drogas; pessoas discriminadas/desrespeitadas por serem identificadas como homossexuais; perdas de trabalho ou financeiras; disputas profissionais ou acadêmicas exageradas, conflitos disciplinares ou litigiosos; separações conjugais e disputa pelos filhos; morte de familiares; desesperança ("As coisas nunca melhoram...") ou isolamento social; dor e doenças crônicas; antecedentes familiares de suicídio (ORGANIZACIÓN MUNDIAL DE LA SALUD, 2014). Todos esses cenários são fatores de risco para o suicídio, por isso o apoio imediato às pessoas acometidas deve ser prioritário, no sentido de estar junto, ouvir, ajudar no que for possível e encaminhar para tratamento especializado.

A biografia de Charles Spurgeon mostra como um pastor, mesmo diante de sofrimentos físico (gota serena hiperuricemia) e mental (depressão recorrente, desencadeada por um incêndio com morte de vários fiéis), mesmo em uma época em que a Medicina e a Psicologia não apresentavam tantos recursos terapêuticos, conseguiu encontrar sentido na vida, mirando no alvo de adorar e glorificar a Deus, proclamando a sua Palavra para milhares de pessoas. Que, mesmo diante de tão grandes tribulações, possamos falar como Charles Spurgeon:

Sofri tanta dor física quanto a maioria aqui presente e também sei tanto sobre a depressão de espírito quanto qualquer um (...) não trocaria com o homem mais saudável, ou com o mais rico, ou com o mais culto, ou com o homem mais eminente em todo o mundo, se tivesse que desistir de minha fé em Jesus Cristo - provada 
como às vezes é. (SPURGEON, 1998, apud ESWINE, 2015, p. 176)

\section{CONSIDERAÇÕES FINAIS}

Considerando os níveis crescentes de pastores que desencadeiam transtornos mentais e os números elevados de suicídio deste público, visto diariamente em jornais na internet e em redes de televisão. É fundamental o desenvolvimento de mais estudos na área, além da quebra de ideais capazes de dificultar o tratamento ou mesmo o acolhimento do sofrimento psíquico desses.

É imprescindível que a igreja atente para tudo o que foi supracitado, percebendo aqueles os quais precisam ser apascentados. O maior engano é achar que os pastores obtêm fé suficiente ou até mesmo superior para lidar com as situações da vida, sendo desnecessário ajudá-los. Contudo, as lutas enfrentadas por tais líderes não são mais fáceis. A teologia traz sim amadurecimento para lidar com as supostas dificuldades, porém, as dores e os sofrimentos são reais e precisam ser tratados. Alguns desses líderes cristãos, diante da depressão ou do burnout, e até de legalismos de algumas denominações exageradamente moralistas, desenvolvem sentimentos agravantes de culpa por omissão ou por ações questionadas inadequadamente.

A teologia, baseada nas verdades da Bíblia e nos dados das confissões de fé cristãs, nos ensinam que o ser humano deve viver para glorificar a Deus e ter alegria nEle. Deus nos deu o livre arbítrio para direcionarmos nossas ações para a honra e glorificação de Cristo, obedecendo à sua Lei (1 CORÍNTIOS 10.31; 1 TESSALONICENCES 5.16-18). E, Ele nos promete que felizes são os que choram ou são perseguidos por fazerem a justiça/vontade de Deus, porque Ele nos consola e nos dá como herança o reino do céu (MATEUS 5.4,10).

Portanto, é necessário que a negligência, no que está relacionado ao cuidado com os pastores, seja derrogada. Esses guerreiros de Deus, muitas vezes feridos e sangrando, precisam de apoio, lazer, mentoria e tratamento amorosos da sua comunidade. 


\section{REFERÊNCIAS}

AMORIM JUNIOR, Delcio Torres; ARAUJO, Diogo Damião Crotti; SILVA, Mario Antonio da. A saúde psicoemocional do pastor e os altos índices de depressão e suicídio. Revista Terra \& Cultura: Cadernos de Ensino e Pesquisa. V. 35, n. 69, jul./dez. 2019.

AMERICAN PSYCHIATRIC ASSOCIATION. Manual diagnóstico e estatístico de transtornos mentais. Tradução de Maria Inês Corrêa Nascimento et al. Revisão técnica de Aristides Volpato Cordioli et al. $5^{\text {a }}$ ed. Porto Alegre: Artmed, 2014.

ANDRADE, José Carlos Drumond. José. Lelivros. São Paulo: José Olympio. Disponível em: http://lelivros.love/book/baixar-livro-josecarlos-drummond-de-andrade-em-pdf-epub-e-mobi/\#tabadditional_information. Acesso em: 23 dez. 2019.

BIBLIOTECA VIRTUAL EM SAÚDE. Localizar Descritor de Assunto: burnout syndrome. Disponível em: https://pesquisa.bvsalud.org/portal/decslocator/?lang=pt\&mode=\&tree_id=F01.145.126.990.367. Acesso em: 23 dez. 2019.

BOVO JÚNIOR, Irineu; BRUNING, Keity Cassiana Seco. A saúde psicoemocional do pastor e os altos índices de depressão e suicídio. Revista Terra e Cultura. V. 35, n. 69, p. 161-168. Disponível em:

http://periodicos.unifil.br/index.php/Revistateste/article/view/118 0/1082. Acesso em: 23 dez. 2019.

BUHR, João R. O sofrimento de Paulo. Revista Ensaios Teológicos, Faculdade Batista Pioneira; Vol. 01, No 02, p.50-71, Dez/2015.

CONRAD, P. The medicalization of society: on the transformation of human conditions into treatable disorders. Baltimore: Johns Hopkins Press, 2007.

1 CORÍNTIOS. In: Bíblia Online. Nova Versão Internacional. Disponível em: https://www.bibliaonline.com.br/nvi/1co/10 . Acesso em: 23 dez. 2019. 
DEJOURS, Christophe; BÈGUE, Florence. Suicídio e trabalho: o que fazer? Brasília: Paralelo, 2010, 128 p.

DEUS, Pérsio Ribeiro Gomes de. Um estudo da depressão em pastores protestantes. Revista Ciências da Religião - História e Sociedade, v.7, N 1, p. 189-202, 2009.

DEUS, Persio Ribeiro Gomes de. As influências do sentimento religioso sobre o cristão portador de depressão. 2008.147 f. Dissertação (Mestrado em Ciências da Religião) - Universidade Presbiteriana Mackenzie, São Paulo, 2008.

EBERT, Clarice; SOBOLL Lis Andrea Pereira. O trabalho pastoral numa análise da Psicodinâmica do Trabalho. Aletheia. N. 30, p. 197-212. 2009.

ESWINE, Zack. A Depressão de Spurgeon: esperança realista em meio à angústia. E-book kindle. Campos, SP: Fiel, 2015.

FRANCIS A. SCHAEFFER INSTITUTE OF CHURCH LEADERSHIP DEVELOPMENT. Statistcs on pastors: 2016 update. Disponível em: http://files.stablerack.com/webfiles/71795/pastorsstatWP2016.pdf . Acesso em: 23 dez. 2019.

FREUDENBERGER, H. J. Staff. Burn-Out. Journal of Social Issues, [s. I.], v. 30, n. 1, p. 159-165, 1974. DOI 10.1111/j.15404560.1974.tb00706.x. Disponível em: http://search-ebscohostcom.ez15.periodicos.capes.gov.br/login.aspx?direct=true\&db=sih \&AN=16394831\&lang=pt-br\&site=ehost-live. Acesso em: 22 dez. 2019.

GOMES, Antonio Maspoli de Araújo. Um olhar sobre depressão e religião numa perspectiva compreensiva. Estudos de Religião. V. 25, n. 40, 81-109, jan./jun. 2011.

GROSCH, William. N.; OLSEN, David. C. Clergy burnout: na integrative approach. Journal of Clinical Psychology. V. 56, n. 5, p. 619-632, 2000.

HERRERA, H. López; PEDROSA, Ignacio; GALINDO, Vicente M. Purificación; SUÁREZ-ÁLVARES, Javier; GALINDO, Villardón, M. Purificación; GARCIA-CUETO, Eduardo. Multivariate analysis of 
burnout syndrome in Latin-American priests. Psicothema. V. 26, n. 2, p. 227-234, 2014.

LEITER, M.; BAKKER. B. A.; MASLACH. C. (Eds.). Burnout at work. New York: Psychology Press. 2014. (Current Issues in Work and Organizational Psychology).

LOTUFO NETO, Francisco. Psiquiatria e Religião: a prevalência de transtornos mentais entre ministros religiosos. 1997, 375 f. Tese (Livre Docência) - Departamento de Psiquiatria, Universidade de São Paulo, 1997.

MASLACH, C; PINES, A. The burn-out syndrome in the day care setting. Child Care Quarterly, June 1977, Vol.6(2), pp.100-113.

MASLACH, Christina; JACKSON, Susan E.; LEITER, Michael P. Maslach Burnout Inventory. In: ZALAQUETT, Carlos P.; WOOD, Richard J. (Ed.). Evaluating Stress: a book of resources. $3^{\mathrm{a}}$. Ed. Scarecrow Press, Londres, 1997. V. 2, p. 190-218.

MASLACH, C.; SCHAUFELI, W. Z.; LEITER, M. P. Job Burnout. Annual Review of Psychology, v. 52, p. 397-422, 2001.

MATHERS, Colin D; LONCAR, Dejan. Projections of Global Mortality and Burden

of Disease from 2002 to 2030. PLoS Med. V. 3, n. 11: p. 2011-2030, 2006. doi:10.

1371/journal.pmed.0030442.

MATEUS. Bíblia Online. Nova Versão Transformadora. Disponível em: https://www.bibliaonline.com.br/nvt/mt/5. Acesso em: 23 dez. 2019.

MÉNDEZ, F. X.; OLIVARES, J.; ROS, M. C. Características clínicas e tratamento da depressão na infância e adolescência. In V. E. Caballo \& M. A. Simón, Manual de Psicologia Clínica Infantil e do Adolescente: Transtornos gerais (pp.139-185). 2005. São Paulo, SP: Santos

NAKANO, Erika Feltrin Marques; NERY, Alberto Domeniconi ; VASCONCELLOS, Esdras Guerreiro. Burnout, discurso do sujeito coletivo e aspectos psicossociais em pastoras e pastores. LifeStyle 
Journal, São Paulo, v. 5, n. 1, p. 25-41, $1^{\circ}$ semestre de 2018. ISSN: 2237-3756.

NIEDERKROTENTHALER, Thomas et al. Role of media reports in completed and prevented suicide: Werther v. Papageno effects. The British Journal of Psychiatry. V. 197, p. 234-243, 2010. doi: 10.1192/bjp.bp.109.074633.

NUNES, Rafael Zaneripe de Souza; SOUZA, Rosimere Vieira da Cruz de; CASTRO, Amanda. Fatores associados à depressão em Líderes Religiosos de uma denominação pentecostal. Id on line Rev. Mult. Psic., 2018, vol.12, n.42, p. 367-382. ISSN: 1081-1179.

ORGANIZAÇÃO MUNDIAL DE SAÚDE. Relatório Mundial da Saúde. Saúde mental: nova concepção, nova esperança. Lisboa, Coordenação Nacional para a Saúde Mental Alto Comissariado da Saúde, Ministério da Saúde de Portugal. 2002.

ORGANIZAÇÃO MUNDIAL DE SAÚDE; ORGANIZAÇÃO MUNDIAL DE MÉDICOS DE FAMÍLIA. Integração da saúde mental nos cuidados de saúde primários: uma perspectiva global. Lisboa, CLIMEPSI Editores, 2008.

ORGANIZACIÓN MUNDIAL DE LA SALUD. Prevención del suicidio: un imperativo global. Washington, DC: OPS, 2014.

ORGANIZAÇÃO PAN-AMERICANA DE SAÚDE, 2018. Folha Informativa: depressão. 2019. Disponível em: https://www.paho.org/bra/index.php?option=com_content\&view= article\&id=5635:folha-informativa-depressao\& ltemid=1095.

Acesso em: 23 dez. 2019.

QUARESMA, Marcos. Suicídio de pastores: uma reflexão necessária. São Paulo, SP: Sepa 2016. Disponível em: http://sepal.org.br/blogsepal/suicidiodepastoreselideresumarefle xaonecessaria/

ROMANOS. In: BÍBLIA Online. Nova Versão Internacional. Disponível em: https://www.bibliaonline.com.br/nvi+nvt/rm/8. Acesso em: 22 dez 2019. 
SILVA, Jetro Ferreira. Síndrome de Burnout entre os pastores adventistas da cidade de São Paulo: causas potenciais e medidas preventivas. Dissertação (Mestrado em Ciências da Religião) Universidade Metodista de São Paulo, São Bernardo do Campo, 2003.

SILVA, Rogério Rodrigues. Profissão Pastor: uma análise psicodinâmica do trabalho de líderes religiosos neopentecostais e tradicionais. 187 f. Dissertação (Mestrado em Psicologia) - Instituto de Psicologia da Universidade de Brasília, Distrito Federal, 2004.

SILVA, Ricardo Ferreira da. Burnout e sua ressonância em ministros religiosos: parâmetros para sua prevenção. 80 f. Dissertação (Mestrado em Ciências da Religião) - Centro de Educação, Filosofia e Teologia, Universidade Presbiteriana Mackenzie, São Paulo, 2018.

STACK, Steven. Religious Activities and Suicide Prevention:

A Gender Specific Analysis. Religions. V. 9, n. 127. 2018. doi:10.3390/rel9040127

1 TESSALONICENSES. Bíblia Online. Nova Versão Internacional. Disponível em: https://www.bibliaonline.com.br/nvi/1ts/5. Acesso em: 23 dez. 2019.

TOMIC, W.; TOMIC, D. M.; EVERS, W. J. G. A question of burnout among reformed church ministers in The Netherlands. Mental Health, Religion \& Culture, [s. I.], v. 7, n. 3, p. 225-247, 2004. DOI 10.1080/13674670310001602472. Disponível em: http://searchebscohost-

com.ez15.periodicos.capes.gov.br/login.aspx?direct=true\&db=sih $\& A N=14387840 \&$ lang=pt-br\&site=ehost-live. Acesso em: 22 dez. 2019.

URIARTE, Dom Juan. A espiritualidade do ministro presbiteral. São Paulo: Edições Loyola, 2000. Disponível em: https://books.google.com.br/books?id=BvkQedxsJFcC\&printsec=fr ontcover\&hl=pt-

BR\&source=gbs_ge_summary_r\&cad $=0 \# v=$ onepage $\& q \& f=$ false. Acesso em: 23 dez. 2019.

WORLD HEALTH ORGANIZATION. Mental Health Action Plan 2013- 
2020. WHO Document Production Services, Geneva, Switzerland, 2013.

WORLD HEALTH ORGANIZATION. Depression and other common mental disorders: global health estimates. World Health Organization, p. 1-24, 2017.

WOLTERS, Albert M. A Criação Restaurada: base bíblica para uma cosmovisão reformada. São Paulo: Cultura Cristã, 2006. 